\title{
A nomogram to predict prognosis in patients undergoing sublobar resection for stage IA non-small-cell lung cancer
}

This article was published in the following Dove Press journal:

Cancer Management and Research

\author{
Heli Yang' \\ Xiangdong $\mathrm{Li}^{2}$ \\ Jialun $\mathrm{Shi}^{2}$ \\ $\mathrm{HaO} \mathrm{Fu}^{\prime}$ \\ Hao Yang ${ }^{2}$ \\ Zhen Liang \\ Hongchao Xiong' \\ Hui Wang ${ }^{3}$ \\ 'Department of Thoracic Surgery I, \\ Key Laboratory of Carcinogenesis and \\ Translational Research (Ministry of \\ Education), Peking University Cancer \\ Hospital and Institute, Haidian, \\ Beijing, People's Republic of China; \\ ${ }^{2}$ Department of Cardiothoracic \\ Surgery, Heping Hospital Affiliated to \\ Changzhi Medical College, Changzhi, \\ Shanxi, People's Republic of China; \\ ${ }^{3}$ Department of Thoracic Surgery, \\ Shandong Provincial Hospital Affiliated \\ to Shandong University, Jinan, \\ Shandong, People's Republic of China
}

Correspondence: Hui Wang

Department of Thoracic Surgery, Shandong Provincial Hospital Affiliated to Shandong University, 324 Jingwu Road, Jinan, Shandong, People's Republic of

China

Tel +8653168773133

Fax +86 53I 8793 774I

Email hfmhui@I63.com
Introduction: This study aimed to develop a practical nomogram to predict prognosis in patients who are undergoing sublobar resection for stage IA non-small-cell lung cancer (NSCLC). Data from Surveillance, Epidemiology, and End Results (SEER) databases were used to construct the nomogram.

Methods: Data from patients undergoing sublobar resection for stage IA NSCLC diagnosed between 2004 and 2014 were extracted from the SEER database. Factors that may predict the outcome were identified using the Kaplan-Meier method and the Cox proportional-hazards model. A nomogram was constructed to predict the 3- and 5-year overall survival (OS) and lung cancer-specific survival (LCSS) rates of these patients. The predictive accuracy of the nomogram was measured using the concordance index ( $C$-index) and calibration curve.

Results: A total of 4,866 patients were selected for this study. Using univariate and multivariate analyses, eight independent prognostic factors associated with OS were identified, including sex $(P<0.001)$, age $(P<0.001)$, race $(P=0.043)$, marital status $(P=0.009)$, pathology $(P=0.004)$, differentiation $(P<0.001)$, tumor size $(P<0.001)$, and surgery $(P=0.001)$, and five independent prognostic factors associated with LCSS were also identified, including sex $(P<0.001)$, age $(P<0.001)$, differentiation $(P<0.001)$, tumor size $(P<0.001)$, and surgery $(P=0.011)$. A nomogram was established based on these results and validated using the internal bootstrap resampling method. The $C$-index of the established nomogram for OS and LCSS was 0.649 (95\% CI: 0.635-0.663) and 0.640 (95\% CI: 0.622-0.658), respectively. The calibration curves for probability of 3-, and 5-year OS and LCSS rates demonstrated good agreement between the nomogram prediction and actual observation.

Conclusion: This innovative nomogram delivered a relatively accurate individual prognostic prediction for patients undergoing sublobar resection for stage IA NSCLC.

Keywords: sublobar resection, stage IA, non-small-cell lung cancer, prognostic factors, nomogram

\section{Introduction}

Lung cancer remains the most common cancer and the leading cause of cancer mortality worldwide, with non-small-cell lung cancer (NSCLC) accounting for approximately $85 \%{ }^{1}$ In recent years, the detection of early-stage lung cancer has increased significantly with the use and extensive application of low-dose and high-resolution spiral computed tomography (CT) screening. ${ }^{2}$ Surgery is the preferred curative approach for early-stage NSCLC, especially for stage IA (T1N0M0). In 1995, the only randomized controlled trial comparing lobectomy and sublobar resection (wedge resection and segmentectomy) was conducted by the Lung Cancer Study Group (LCSG) and resulted in 
standardized lobectomy as the optimal treatment strategy for stage IA NSCLC. Sublobar resection was negatively assessed for its high rate of local recurrence and the tendency of having a worse overall survival (OS) outcome. ${ }^{3}$ However, the proportion of sublobar resections has been increasing yearly and the survival benefit of lobectomy over sublobar resection has been declining over the past 2 decades. ${ }^{4}$ Accumulated clinical evidence has demonstrated that sublobar resection may have an important role in stage IA NSCLC treatment. However, due to the lack of large cohort studies to determine prognostic factors affecting patients undergoing sublobar resection, the efficacy of sublobar resection has not been fully evaluated..$^{5}$ Nomogram, which creates a plain visual representation of a statistical predictive model yielding a numerical probability of a clinical outcome, is widely used to predict prognosis in cancer patients. ${ }^{6}$ Nevertheless, to our knowledge, the application of nomogram for patients undergoing sublobar resection for stage IA NSCLC has not been utilized. We sought to identify prognostic factors for patients undergoing sublobar resection for stage IA NSCLC and to establish a nomogram to predict the 3- and 5-year OS and lung cancer-specific survival (LCSS) rates of these patients.

\section{Methods}

\section{Data source}

The data used in this study were extracted from the Surveillance, Epidemiology, and End Results (SEER) registry program of the National Cancer Institute. The SEER database, which includes 18 registries and covers approximately $28 \%$ of the US population, is an authoritative collection of data on cancer incidence, prevalence, population-based variables, primary tumor characteristics, treatment, and mortality. ${ }^{7}$ SEER database is freely available with patient anonymization and, approval from institutional review board was not required. This database has been utilized in several studies to determine prognostic factors associated with a variety of cancers. ${ }^{8-13}$

\section{Study population}

Data between 2004 and 2014 were retrieved using the SEER*Stat software. We limited our analysis to data collected from 2004 . This was because data for lung cancer with the T stage component in the SEER database were derived from collaborative stage (CS) coded fields and was only available from 2004. Inclusion criteria were as follows: ICD-O-3 site code C34.0-C34.9; ICD-O-3 morphology code did not index small-cell lung cancer $(8,041,8,042,8,043,8,044$, and $8,045)$; stage IA (T1N0M0); surgical approach was sublobar resection (wedge resection or segmentectomy); and NSCLC was the only primary or first of two or more primary cancers. Exclusion criteria were as follows: patients' age at diagnosis was younger than 18 years and patients with missing or incomplete data on race, marital status, differentiation, tumor size and location, type of surgery, survival status, cause of death, and follow-up status of less than 1 month.

The following information was obtained for each patient from the SEER database: patient demographics (year of diagnosis, sex, age at diagnosis, race, and marital status), clinicopathological characteristics of the tumors (involved lobe, tumor size, histological type and differentiation, and TNM stage); type of pulmonary surgery (wedge resection or segmentectomy) and survival information (vital status, cause of death, cancer-specific death, and survival months).

Several variables were further divided into different subgroups to facilitate the analysis. Patients were divided into three groups based on age at diagnosis $(<60,60-75$, and $>75$, representing adult, older adult, and senior adult, respectively). Race was divided into white, black, and others (American Indian/Alaska native, Asian/Pacific Islanders, and so on). Marital status was classified as married, divorced, and others (including widowed, never married, single, unmarried, or domestic partner). Histological type was classified as adenocarcinoma (AC), squamous cell carcinoma (SC), and others (large cell carcinoma, adenosquamous carcinoma, and other types not categorized as AC or SC). Histological differentiation was categorized as grades I-IV, which represented well differentiated, moderately differentiated, poorly differentiated, and undifferentiated, respectively. Tumor size was further divided into three groups based on the American Joint Committee on Cancer/Union for International Cancer Control (AJCC/UICC) eighth edition staging system $(<1.0$, $1.0-2.0$, and $>2.0$ ).

OS was calculated as the number of months from surgery to death due to any cause. LCSS was calculated as the number of months from surgery to death due to NSCLC. Patients who died from other causes or were still alive at the end of the study period were defined as censored.

\section{Statistical analyses}

Statistical analysis was performed using SPSS (Version 22.0; IBM Corporation, Armonk, NY, USA). The Kaplan-Meier method was used to describe the prognostic effect of each factor on survival, and the survival curve was compared using the log-rank test. A Cox proportional-hazards model was used for multivariate analysis.

Based on the results of the multivariate analysis, a nomogram was constructed using the rms package in $\mathrm{R}$ Version 
3.4.4. ${ }^{14}$ The maximum score for each factor was defined as 100. Concordance index ( $C$-index) was utilized to measure the performance of the nomogram, and the calibration curves were graphed to compare nomogram-predicted vs actual observed survival probability. Bootstraps of 1,000 re-samples were used for analysis. $P$-value $<0.05$ was considered statistically significant.

\section{Results}

\section{Patient characteristics}

Based on the inclusion and exclusion criteria, we identified 4,866 eligible patients undergoing sublobar resection for stage IA NSCLC from 2004 to 2014 in the SEER database. The flow diagram for patient selection is displayed in Figure 1. Patient characteristics are summarized in Table 1. The majority of the patients were female $(2,736 ; 56.2 \%)$, white $(4,239 ; 87.1 \%)$, and married $(2,729 ; 56.1 \%)$. Of the 4,866 patients, $53.8 \%(2,620)$ were between the ages of 60 and 75 years, $29.3 \%(1,425)$ were older than 75 years, and $16.9 \%$ (821) were younger than 60 years. The upper lobe $(3,134,64.4 \%)$ was the most frequently affected site, followed by the lower lobe $(1,543,31.7 \%)$, while the middle lobe $(189,3.9 \%)$ was the site least affected. With regard to histology type, $\mathrm{AC}(2,911,59.8 \%)$ was the most common,

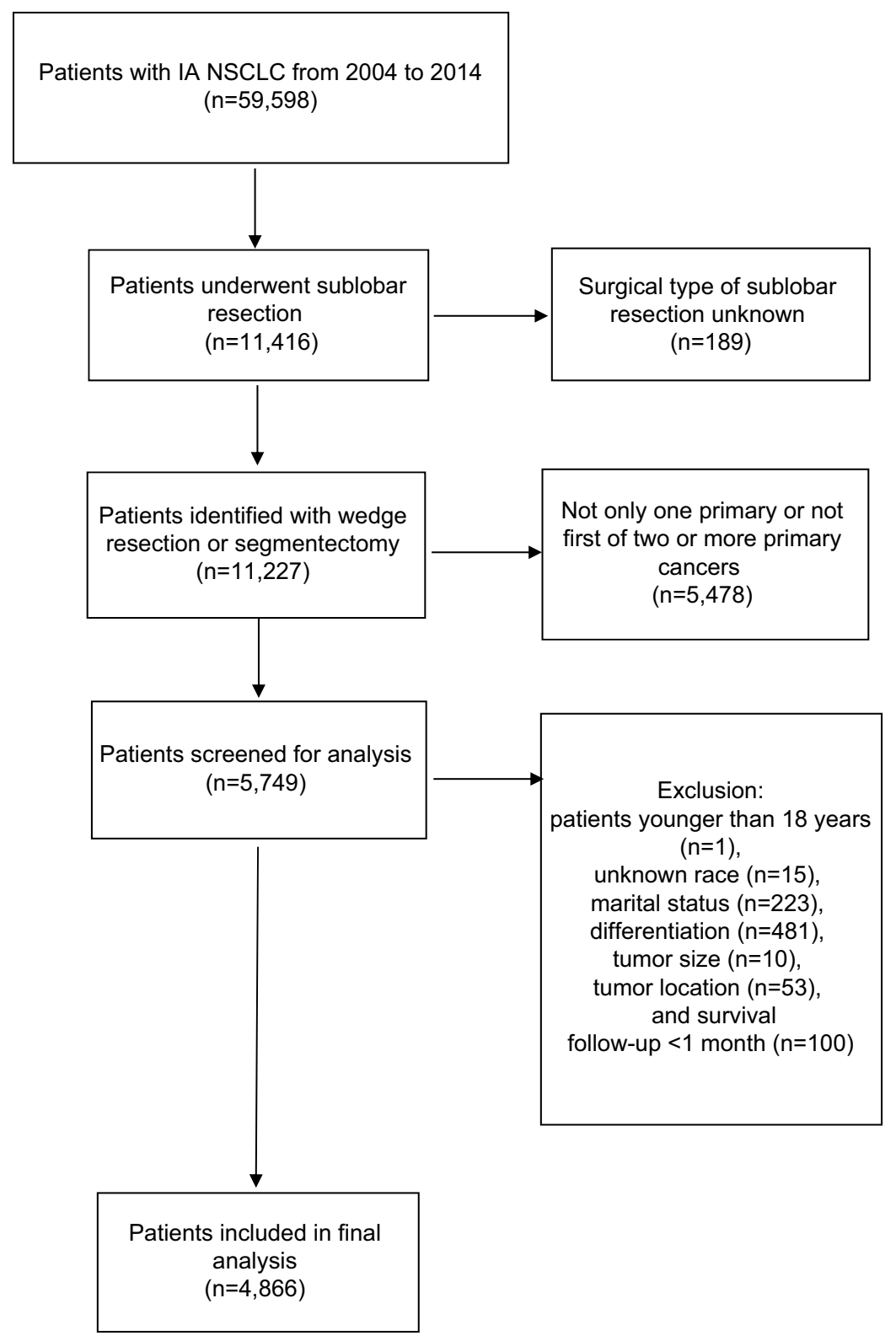

Figure I The flow diagram of the patient selection. Abbreviation: NSCLC, non-small-cell lung cancer. 
Table I Patient characteristics of 3- and 5-year OS and LCSS

\begin{tabular}{|c|c|c|c|c|c|c|}
\hline \multirow[t]{2}{*}{ Characteristics } & \multirow{2}{*}{$\begin{array}{l}\text { Number of } \\
\text { patients }\end{array}$} & \multirow[t]{2}{*}{ Percentage } & \multicolumn{2}{|l|}{ OS (\%) } & \multicolumn{2}{|c|}{ LCSS (\%) } \\
\hline & & & 3-year & 5-year & 3-year & 5-year \\
\hline Total & 4,866 & 100 & & & & \\
\hline \multicolumn{7}{|l|}{ Sex } \\
\hline Male & 2,130 & 43.8 & $68.4 \pm 1.1$ & $51.8 \pm 1.3$ & $79.7 \pm 1.0$ & $70.0 \pm 1.3$ \\
\hline Female & 2,736 & 56.2 & $78.7 \pm 0.9$ & $63.9 \pm 1.1$ & $86.3 \pm 0.7$ & $77.3 \pm 1.0$ \\
\hline \multicolumn{7}{|l|}{ Age (years) } \\
\hline$<60$ & 821 & 16.9 & $82.7 \pm 1.5$ & $72.4 \pm 1.9$ & $88.0 \pm 1.3$ & $81.3 \pm 1.7$ \\
\hline $60-75$ & 2,620 & 53.8 & $76.2 \pm 0.9$ & $61.4 \pm 1.2$ & $85.1 \pm 0.8$ & $75.6 \pm 1.1$ \\
\hline$>75$ & $\mathrm{I}, 425$ & 29.3 & $65.7 \pm 1.4$ & $45.7 \pm 1.6$ & $77.8 \pm 1.3$ & $67.1 \pm 1.6$ \\
\hline \multicolumn{7}{|l|}{ Race } \\
\hline White & 4,239 & 87.1 & $73.7 \pm 0.8$ & $57.7 \pm 0.9$ & $83.0 \pm 0.7$ & $73.5 \pm 0.9$ \\
\hline Black & 398 & 8.2 & $75.5 \pm 2.4$ & $60.7 \pm 2.9$ & $83.6 \pm 2.1$ & $74.6 \pm 2.7$ \\
\hline Others & 229 & 4.7 & $82.0 \pm 2.9$ & $70.5 \pm 3.8$ & $90.9 \pm 2.2$ & $85.5 \pm 3.0$ \\
\hline \multicolumn{7}{|l|}{ Marital status } \\
\hline Married & 2,729 & 56.1 & $74.8 \pm 0.9$ & $60.1 \pm 1.2$ & $83.4 \pm 0.8$ & $74.9 \pm 1.1$ \\
\hline Divorced & 626 & 12.9 & $74.1 \pm 1.9$ & $57.6 \pm 2.4$ & $82.3 \pm 1.7$ & $71.0 \pm 2.3$ \\
\hline Others & $\mid, 5 \mathrm{I}$ & 31.1 & $73.1 \pm 1.3$ & $56.1 \pm 1.6$ & $84.0 \pm 1.1$ & $74.2 \pm 1.5$ \\
\hline \multicolumn{7}{|l|}{ Lobe } \\
\hline Upper & 3,134 & 64.4 & $73.5 \pm 0.9$ & $57.8 \pm 1.1$ & $83.4 \pm 0.8$ & $74.2 \pm 1.0$ \\
\hline Middle & 189 & 3.9 & $77.3 \pm 3.4$ & $65.7 \pm 4.2$ & $85.3 \pm 3.0$ & $78.4 \pm 3.7$ \\
\hline Lower & $\mathrm{I}, 543$ & 31.7 & $75.2 \pm 1.2$ & $59.0 \pm 1.6$ & $83.4 \pm 1.1$ & $73.6 \pm 1.5$ \\
\hline \multicolumn{7}{|l|}{ Pathology } \\
\hline AC & 2,911 & 59.8 & $78.5 \pm 0.9$ & $63.9 \pm 1.1$ & $86.0 \pm 0.7$ & $76.7 \pm 1.0$ \\
\hline SC & $\mathrm{I}, 442$ & 29.6 & $66.4 \pm 1.4$ & $48.5 \pm 1.6$ & $78.6 \pm 1.2$ & $69.0 \pm 1.6$ \\
\hline Others & 513 & 10.5 & $72.4 \pm 2.2$ & $58.0 \pm 2.7$ & $82.5 \pm 2.0$ & $74.6 \pm 2.5$ \\
\hline \multicolumn{7}{|l|}{ Differentiation } \\
\hline 1 & $I, 154$ & 23.7 & $86.0 \pm 1.2$ & $75.7 \pm 1.6$ & $91.7 \pm 1.0$ & $86.0 \pm 1.3$ \\
\hline II & 2,175 & 44.7 & $73.8 \pm I .1$ & $56.3 \pm 1.3$ & $83.4 \pm 0.9$ & $72.6 \pm 1.2$ \\
\hline III & $\mathrm{I}, 444$ & 29.7 & $66.2 \pm 1.4$ & $49.9 \pm 1.5$ & $77.4 \pm 1.2$ & $67.7 \pm 1.5$ \\
\hline IV & 93 & 1.9 & $71.7 \pm 4.8$ & $56.2 \pm 5.6$ & $81.7 \pm 4.3$ & $72.3 \pm 5.3$ \\
\hline \multicolumn{7}{|l|}{ Size $(\mathrm{cm})$} \\
\hline$<1.0$ & 859 & 17.7 & $81.5 \pm 1.5$ & $68.4 \pm 2.0$ & $88.8 \pm 1.3$ & $81.1 \pm 1.7$ \\
\hline $1.0-2.0$ & 2,791 & 57.4 & $76.5 \pm 0.9$ & $59.8 \pm 1.1$ & $84.9 \pm 0.8$ & $75.1 \pm I .1$ \\
\hline$>2.0$ & 1,216 & 25.0 & $64.0 \pm 1.5$ & $49.1 \pm 1.7$ & $76.3 \pm 1.4$ & $67.2 \pm 1.7$ \\
\hline \multicolumn{7}{|l|}{ Surgery } \\
\hline w & 3,838 & 78.9 & $73.5 \pm 0.8$ & $57.6 \pm 1.0$ & $83.0 \pm 0.7$ & $73.6 \pm 0.9$ \\
\hline$S$ & 1,028 & 21.1 & $76.9 \pm 1.5$ & $62.2 \pm 1.9$ & $85.1 \pm 1.3$ & $76.5 \pm 1.7$ \\
\hline
\end{tabular}

Abbreviations: AC, adenocarcinoma; LCSS, lung cancer-specific survival; OS, overall survival; S, segmentectomy; SC, squamous cell carcinoma; W, wedge resection.

followed by SC $(1,442,29.6 \%)$ and others $(513,10.5 \%)$. With regard to histological differentiation, grade II was the most prominent $(2,175,44.7 \%)$, followed by grade III $(1,444$, $29.7 \%$ ), grade I $(1,154,23.7 \%)$, and grade IV (93, 1.9\%). A total of $57.4 \%(2,791)$ of patients had tumors between 1 and $2 \mathrm{~cm}$ in diameter, followed by $25.0 \%(1,216)$ with tumors greater than $2 \mathrm{~cm}$ and $17.7 \%$ (859) with tumors less than $1 \mathrm{~cm}$. Majority of the 4,866 patients underwent pulmonary wedge resection $(3,838,78.9 \%)$, while only $21.1 \%(1,028)$ of the patients underwent segmentectomy.

\section{Survival analysis}

Of the 4,866 patients, 3,882 patients had NSCLC while 984 patients had NSCLC and other primary cancers. The median follow-up period after sublobar resection was 37 (range, $1-131)$ months. A total of 1,873 deaths were reported during the follow-up period, including 1,030 deaths from lung cancer and 843 deaths from other causes. The cumulative 5-year OS and LCSS after surgery were 58.5 and $74.1 \%$, respectively (Figure 2)

In terms of OS, all 4,866 patients were included in the univariate analysis and the results are listed in Table 2 (the Kaplan-Meier curves are shown in Figure S1). Of the demographic data, sex $(P<0.001)$, age $(P<0.001)$, race $(P=0.015)$, and marital status $(P=0.040)$ were found to significantly influence prognosis. With regard to clinicopathological factors, pathology $(P<0.001)$, differentiation $(P<0.001)$, tumor size $(P<0.001)$, and surgery type $(P=0.005)$ were also prognostic 


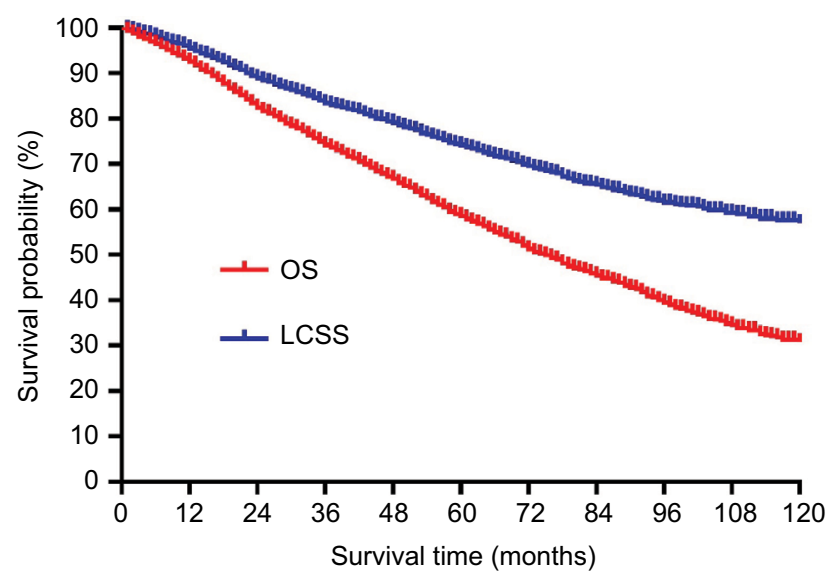

Figure 2 OS and LCSS curves of all patients.

Abbreviations: LCSS, lung cancer-specific survival; OS, overall survival. factors influencing OS. All significant prognostic factors derived from univariate analysis were used for multivariate analysis. The results from Cox proportional-hazards model analyses are listed in Table 2. Results showed that sex $(P<0.001)$, age $(P<0.001)$, race $(P=0.043)$, marital status $(P=0.009)$, pathology $(P=0.004)$, differentiation $(P<0.001)$, size $(P<0.001)$, and surgery $(P=0.001)$ remained independent prognostic factors for OS.

Regarding LCSS, all 4,866 patients were included for univariate analysis and the results are listed in Table 3 (the KaplanMeier curves are shown in Figure $\mathrm{S} 2)$. For demographic data, sex $(P<0.001)$, age $(P<0.001)$, and race $(P=0.040)$ were found to significantly influence prognosis. For clinicopathological

Table 2 Univariate and multivariate Cox regression analyses estimating the risk factors for OS of IA NSCLC

\begin{tabular}{|c|c|c|c|c|c|c|}
\hline \multirow[t]{2}{*}{ Characteristics } & \multicolumn{3}{|c|}{ Univariate } & \multicolumn{3}{|c|}{ Multivariate } \\
\hline & HR & $95 \% \mathrm{Cl}$ & $P$ & HR & $95 \% \mathrm{Cl}$ & $P$ \\
\hline Sex & & & $<0.001$ & & & $<0.001$ \\
\hline Male & Ref & & & Ref & & \\
\hline Female & 0.671 & $0.6|8-0.74|$ & $<0.001$ & 0.693 & $0.630-0.762$ & $<0.001$ \\
\hline Age (years) & & & $<0.001$ & & & $<0.001$ \\
\hline$<60$ & Ref & & & Ref & & \\
\hline $60-75$ & 1.505 & $1.298-1.746$ & $<0.001$ & 1.434 & $1.235-1.665$ & $<0.001$ \\
\hline$>75$ & 2.470 & $2.121-2.876$ & $<0.001$ & 2.285 & $1.955-2.672$ & $<0.001$ \\
\hline Race & & & 0.015 & & & 0.043 \\
\hline White & Ref & & & Ref & & \\
\hline Black & 0.899 & $0.759-1.064$ & 0.215 & 0.948 & $0.799-1.126$ & 0.545 \\
\hline Others & 0.721 & $0.568-0.916$ & 0.007 & 0.739 & $0.58 I-0.940$ & 0.014 \\
\hline Marital status & & & 0.040 & & & 0.009 \\
\hline Married & Ref & & & Ref & & \\
\hline Divorced & 1.093 & $0.952-1.255$ & 0.205 & 1.229 & $1.068-1.414$ & 0.004 \\
\hline Others & 1.134 & $1.026-1.253$ & 0.014 & I. 107 & $0.996-1.230$ & 0.060 \\
\hline Lobe & & & 0.185 & & & NS \\
\hline Upper & Ref & & & NS & & \\
\hline Middle & 0.825 & $0.645-1.055$ & 0.126 & NS & NS & NS \\
\hline Lower & $0.94 I$ & $0.852-1.040$ & 0.231 & NS & NS & NS \\
\hline Pathology & & & $<0.001$ & & & 0.004 \\
\hline$A C$ & Ref & & & Ref & & \\
\hline SC & 1.623 & I.473-1.787 & $<0.001$ & 1.189 & $1.072-1.318$ & 0.001 \\
\hline Others & 1.208 & $1.035-1.409$ & 0.016 & 1.145 & $0.970-1.352$ & 0.109 \\
\hline Differentiation & & & $<0.001$ & & & $<0.001$ \\
\hline I & Ref & & & Ref & & \\
\hline II & 1.910 & $1.660-2.197$ & $<0.001$ & 1.874 & $1.536-2.285$ & $<0.001$ \\
\hline III & 2.383 & $2.064-2.75$ I & $<0.001$ & 2.242 & $1.817-2.765$ & $<0.001$ \\
\hline IV & 1.807 & $1.323-2.468$ & $<0.001$ & 1.703 & I.087-2.668 & 0.020 \\
\hline Size $(\mathrm{cm})$ & & & $<0.001$ & & & $<0.001$ \\
\hline$<1.0$ & Ref & & & Ref & & \\
\hline $1.0-2.0$ & 1.463 & $1.267-1.688$ & $<0.001$ & 1.297 & $1.123-1.498$ & $<0.001$ \\
\hline$>2.0$ & 2.098 & I.802-2.444 & $<0.001$ & 1.728 & $1.480-2.017$ & $<0.001$ \\
\hline Surgery & & & 0.005 & & & 0.001 \\
\hline W & Ref & & & Ref & & \\
\hline$S$ & 0.847 & $0.754-0.951$ & 0.005 & 0.826 & $0.734-0.928$ & 0.001 \\
\hline
\end{tabular}

Note: Not significant (NS), $P$-value $>0.05$.

Abbreviations: AC, adenocarcinoma; LCSS, lung cancer-specific survival; NSCLC, non-small-cell lung cancer; OS, overall survival; Ref, reference; S, segmentectomy; SC, squamous cell carcinoma; $\mathrm{W}$, wedge resection. 
Table 3 Univariate and multivariate Cox regression analyses estimating the risk factors for LCSS of IA NSCLC

\begin{tabular}{|c|c|c|c|c|c|c|}
\hline \multirow[t]{2}{*}{ Characteristics } & \multicolumn{3}{|c|}{ Univariate } & \multicolumn{3}{|c|}{ Multivariate } \\
\hline & HR & $95 \% \mathrm{Cl}$ & $P$ & HR & $95 \% \mathrm{Cl}$ & $P$ \\
\hline Sex & & & $<0.001$ & & & $<0.001$ \\
\hline Male & Ref & & & Ref & & \\
\hline Female & 0.721 & $0.638-0.814$ & $<0.001$ & 0.761 & $0.670-0.865$ & $<0.001$ \\
\hline Age (years) & & & $<0.001$ & & & $<0.001$ \\
\hline$<60$ & Ref & & & Ref & & \\
\hline $60-75$ & 1.281 & $1.063-1.542$ & 0.009 & 1.237 & $1.026-1.493$ & 0.026 \\
\hline$>75$ & 1.858 & $1.530-2.257$ & $<0.001$ & 1.792 & $1.466-2.189$ & $<0.001$ \\
\hline Race & & & 0.040 & & & 0.056 \\
\hline White & Ref & & & Ref & & \\
\hline Black & 1.012 & $0.815-1.257$ & 0.911 & 1.052 & $0.844-1.312$ & 0.650 \\
\hline Others & 0.645 & $0.458-0.909$ & 0.012 & 0.665 & $0.47 \mathrm{I}-0.937$ & 0.020 \\
\hline Marital status & & & 0.223 & & & NS \\
\hline Married & Ref & & & NS & & \\
\hline Divorced & 1.166 & $0.975-1.394$ & 0.092 & NS & NS & NS \\
\hline Others & 1.005 & $0.876-1.154$ & 0.939 & NS & NS & NS \\
\hline Lobe & & & 0.652 & & & NS \\
\hline Upper & Ref & & & NS & & \\
\hline Middle & 0.863 & $0.620-1.201$ & 0.382 & NS & NS & NS \\
\hline Lower & 1.013 & $0.887-1.156$ & 0.852 & NS & NS & NS \\
\hline Pathology & & & $<0.001$ & & & 0.733 \\
\hline$A C$ & Ref & & & Ref & & \\
\hline SC & 1.419 & $1.243-1.619$ & $<0.001$ & 1.044 & $0.907-1.201$ & $0.55 \mathrm{I}$ \\
\hline Others & 1.179 & $0.960-1.448$ & 0.115 & 1.077 & $0.864-1.342$ & 0.510 \\
\hline Differentiation & & & $<0.001$ & & & $<0.001$ \\
\hline I & Ref & & & Ref & & \\
\hline ॥ & 2.048 & $1.688-2.484$ & $<0.001$ & 1.874 & $1.536-2.285$ & $<0.001$ \\
\hline III & 2.545 & $2.088-3.102$ & $<0.001$ & 2.242 & $1.817-2.765$ & $<0.001$ \\
\hline IV & 1.994 & $1.308-3.038$ & 0.001 & 1.703 & I.087-2.668 & 0.020 \\
\hline Size $(\mathrm{cm})$ & & & $<0.001$ & & & $<0.001$ \\
\hline$<1.0$ & Ref & & & Ref & & \\
\hline $1.0-2.0$ & 1.400 & $1.157-1.695$ & 0.001 & 1.265 & $1.043-1.534$ & 0.017 \\
\hline$>2.0$ & 2.054 & $1.676-2.516$ & $<0.001$ & 1.736 & $1.412-2.133$ & $<0.001$ \\
\hline Surgery & & & 0.035 & & & 0.011 \\
\hline W & Ref & & & Ref & & \\
\hline $\mathrm{S}$ & 0.845 & $0.722-0.988$ & 0.035 & 0.813 & $0.694-0.953$ & 0.011 \\
\hline
\end{tabular}

Note: Not significant (NS), $P$-value $>0.05$.

Abbreviations: AC, adenocarcinoma; LCSS, lung cancer-specific survival; NSCLC, non-small-cell lung cancer; OS, overall survival; Ref, reference; S, segmentectomy; SC, squamous cell carcinoma; $\mathrm{W}$, wedge resection.

factors, differentiation $(P<0.001)$, tumor size $(P<0.001)$, and surgery type $(P=0.035)$ were also prognostic factors influencing LCSS. All significant prognostic factors derived from univariate analysis were used for multivariate analysis. The results from Cox proportional-hazards model analyses are listed in Table 3. Results demonstrated that sex $(P<0.001)$, age $(P<0.001)$, differentiation $(P<0.001)$, size $(P<0.001)$, and surgery $(P=0.011)$ remained independent prognostic factors for OS, whereas race $(P=0.056)$ and histological type $(P=0.733)$ were not independent prognostic factors for LCSS.

The formulated nomogram based on independent prognostic factors identified by Cox proportional-hazards model is shown in Figure 3. We used this visual predictive tool to easily obtain the probability of 3-year and 5-year OS and LCSS rates of patients with stage IA NSCLC who underwent sublobar resection. First, each independent prognostic factor was segregated into two or more levels to correspond to score values based on the point scale on the top of the nomogram. Then, the sum of the points was calculated for each variable for each patient to obtain the 3- and 5-year OS and LCSS rates corresponding to the bottom point scale of the nomogram. The model demonstrated good accuracy with the $C$-index of 0.649 (95\% CI: $0.635-0.663$ ) for OS and 0.640 (95\% CI: $0.622-0.658$ ) for LCSS. This indicated a relatively 


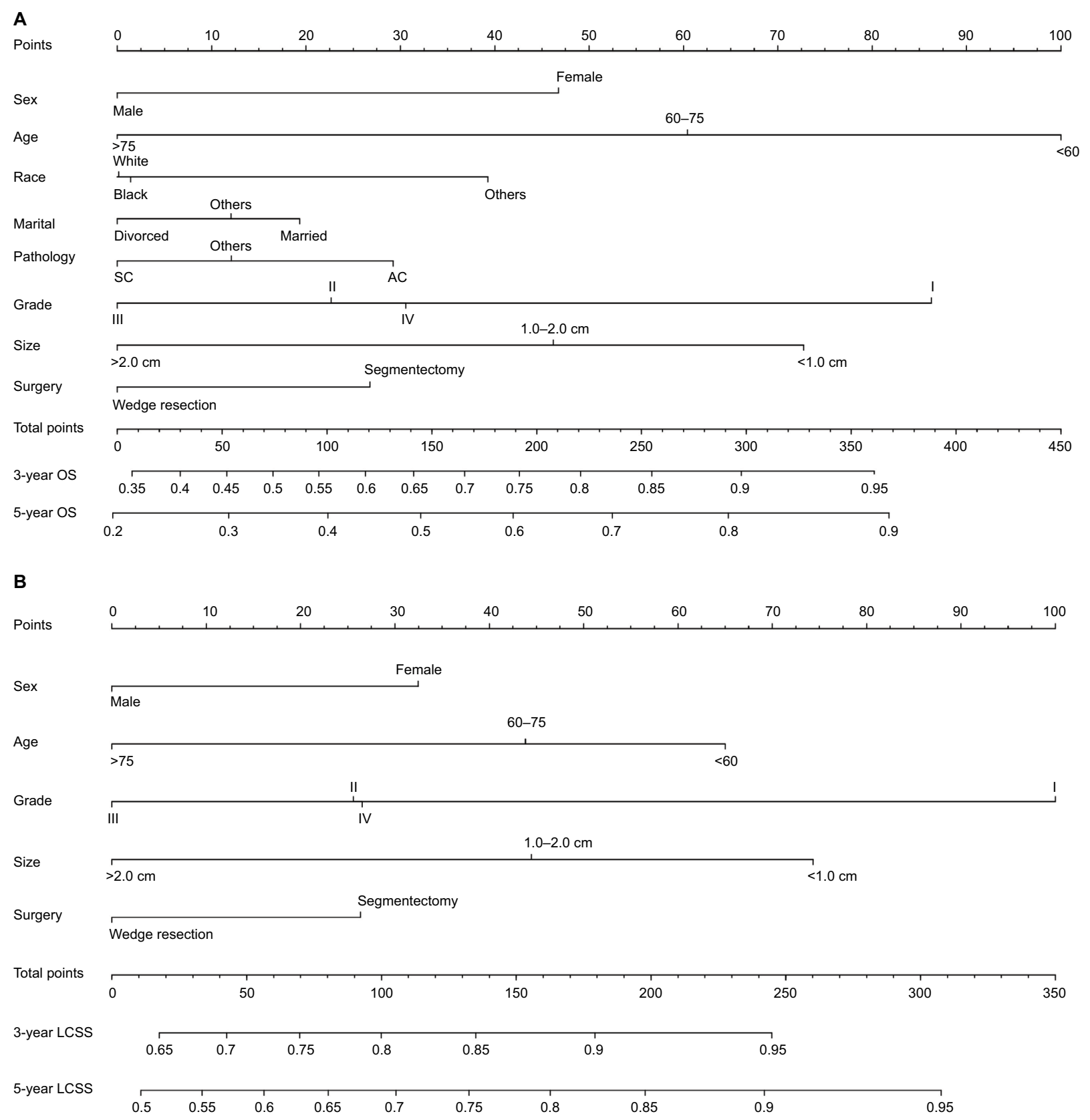

Figure 3 (A) Nomogram for the prediction of 3- and 5-year OS rates of patients undergoing sublobar resection for stage IA NSCLC. (B) Nomogram for the prediction of 3- and 5-year LCSS rates of patients undergoing sublobar resection for stage IA NSCLC.

Abbreviations: AC, adenocarcinoma; LCSS, lung cancer-specific survival; OS, overall survival; SC, squamous cell carcinoma.

good model discriminative ability. The calibration curves are shown in Figures 4 and 5, with an optimal agreement between nomogram prediction and actual observation for 3- and 5-year OS and LCSS probabilities.

\section{Discussion}

Multiple factors have led to the dramatic increase in the number of sublobar resections for patients with stage IA NSCLC. This has led to the heightened interest to determine its overall efficacy. Lung cancer screening using computed tomography encouraged by the National Lung Screening Trial (NLST) has resulted in the early detection of cancer that is localized and of smaller tumor size. ${ }^{2}$ In addition, extensive and in-depth understanding of histopathological behavior of lung $\mathrm{AC}$ within different prognostic subgroups have directly impacted surgical resection strategies. ${ }^{15}$ Third, with an aging population, more elderly patients with significant medical comorbidities and impaired lung function 

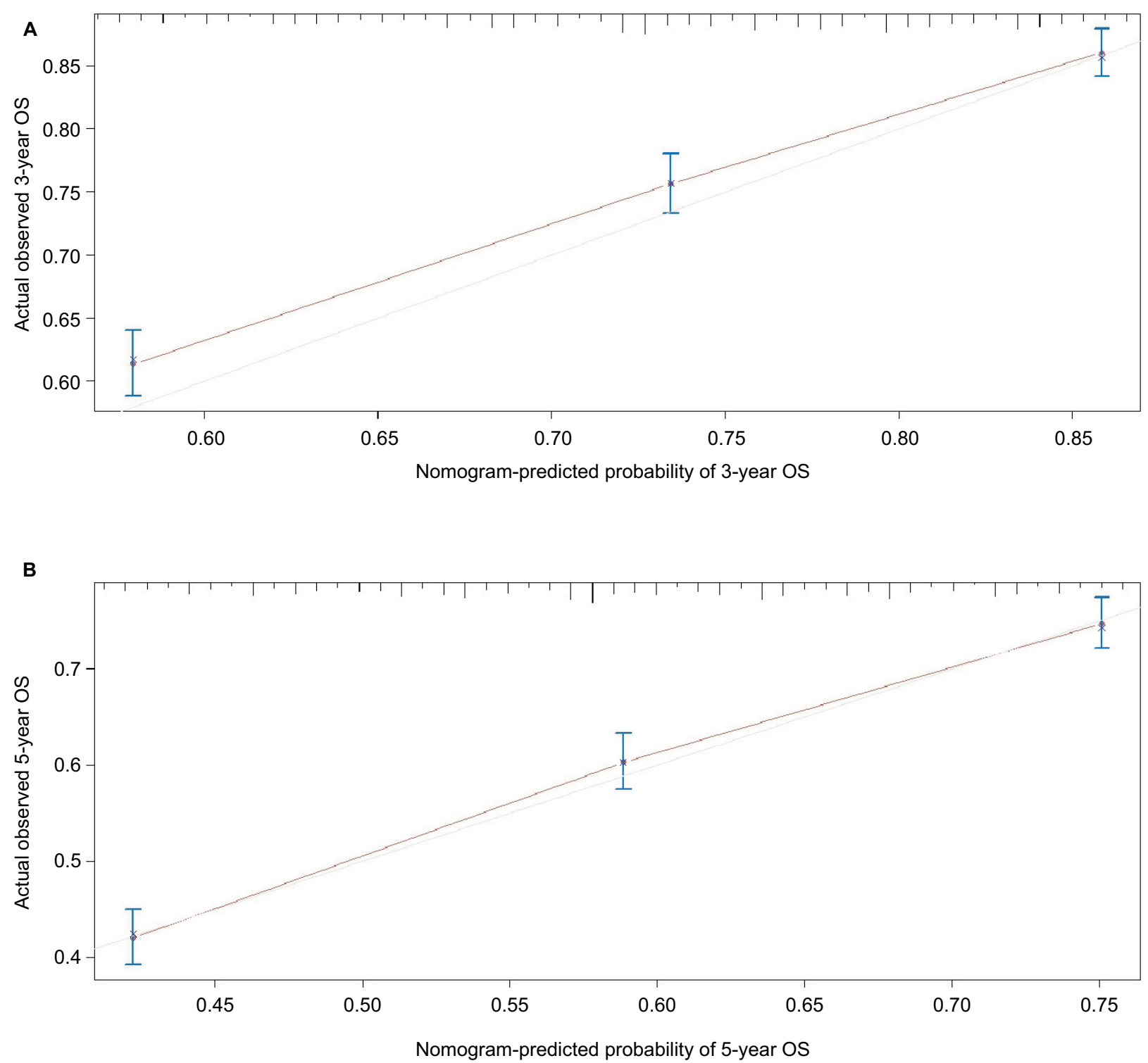

Figure 4 (A) Calibration curve of the nomogram for predicting 3-year OS rates of patients undergoing sublobar resection for stage IA NSCLC. (B) Calibration curve of the nomogram for predicting 5-year OS rates of patients undergoing sublobar resection for stage IA NSCLC.

Abbreviations: NSCLC, non-small-cell lung cancer; OS, overall survival.

that have been diagnosed with lung cancer and are unable to tolerate lobectomies have undergone sublobar resections. ${ }^{16}$ Fourth, new technologies such as stereotactic ablative radiotherapy (SABR), which warrants additional considerations for early-stage NSCLC, compels surgery to be minimally invasive. ${ }^{17}$ However, there is a lack of large cohort studies for the prognosis of early-stage NSCLC patients who have undergone sublobar resection. Due to the lack of appropriate cohort studies, prediction models and tools are uncommon. To our knowledge, this study is the first to attempt to establish a prognostic nomogram for patients undergoing sublobar resection for stage IA NSCLC. Using a large cohort of 4,866 patients' data from the SEER database, we were able to obtain relatively precise long-term survival estimates for patients who had undergone sublobar resection.

Segmentectomy is distinct from wedge resection in terms of efficacy. Segmentectomy is a better treatment option compared to wedge resection and may lead to improved survival in patients with stage IA NSCLC. Our analysis demonstrated that segmentectomy was superior to wedge resection for stage IA NSCLC patients, both for OS and LCSS. The metaanalysis conducted by Cao et a $1^{18}$ demonstrated that segmentectomy had the same OS and disease-free survival (DFS) with lobectomy in specifically selected patients (patients 


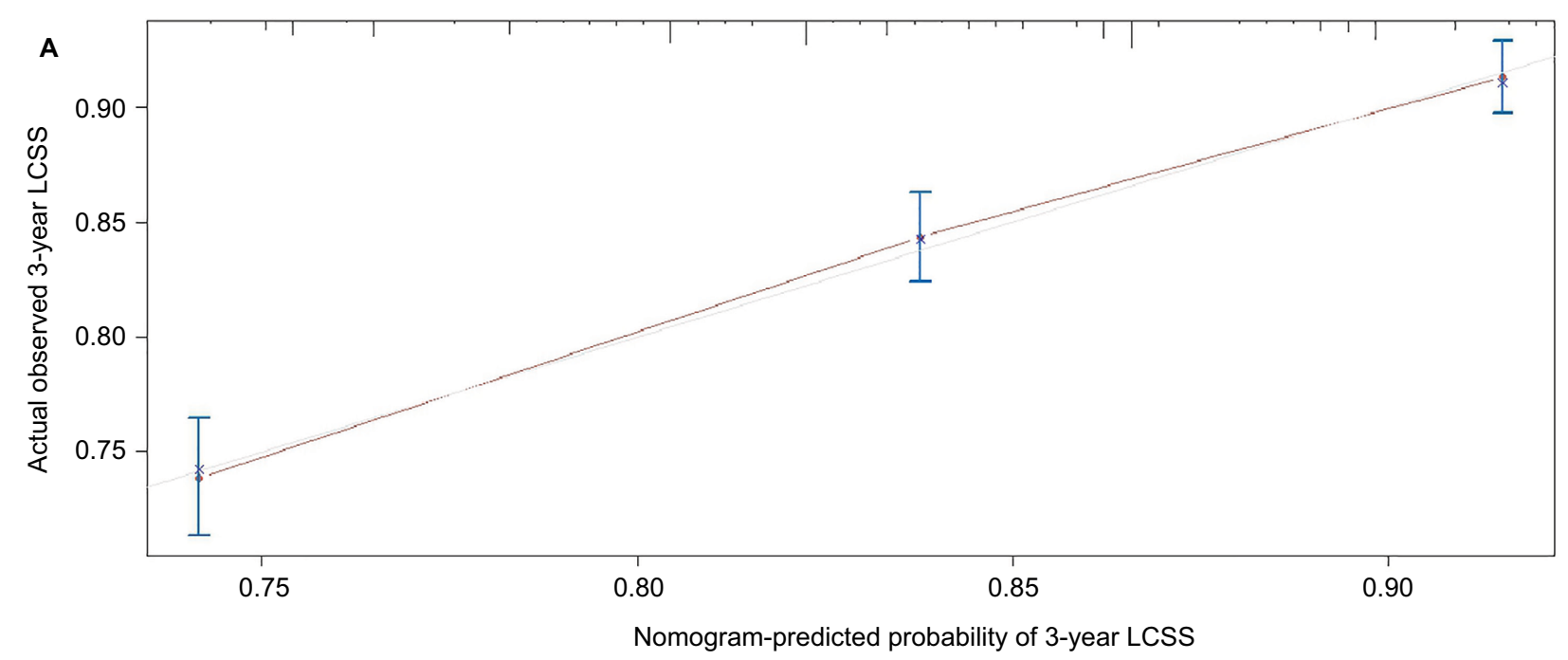

B

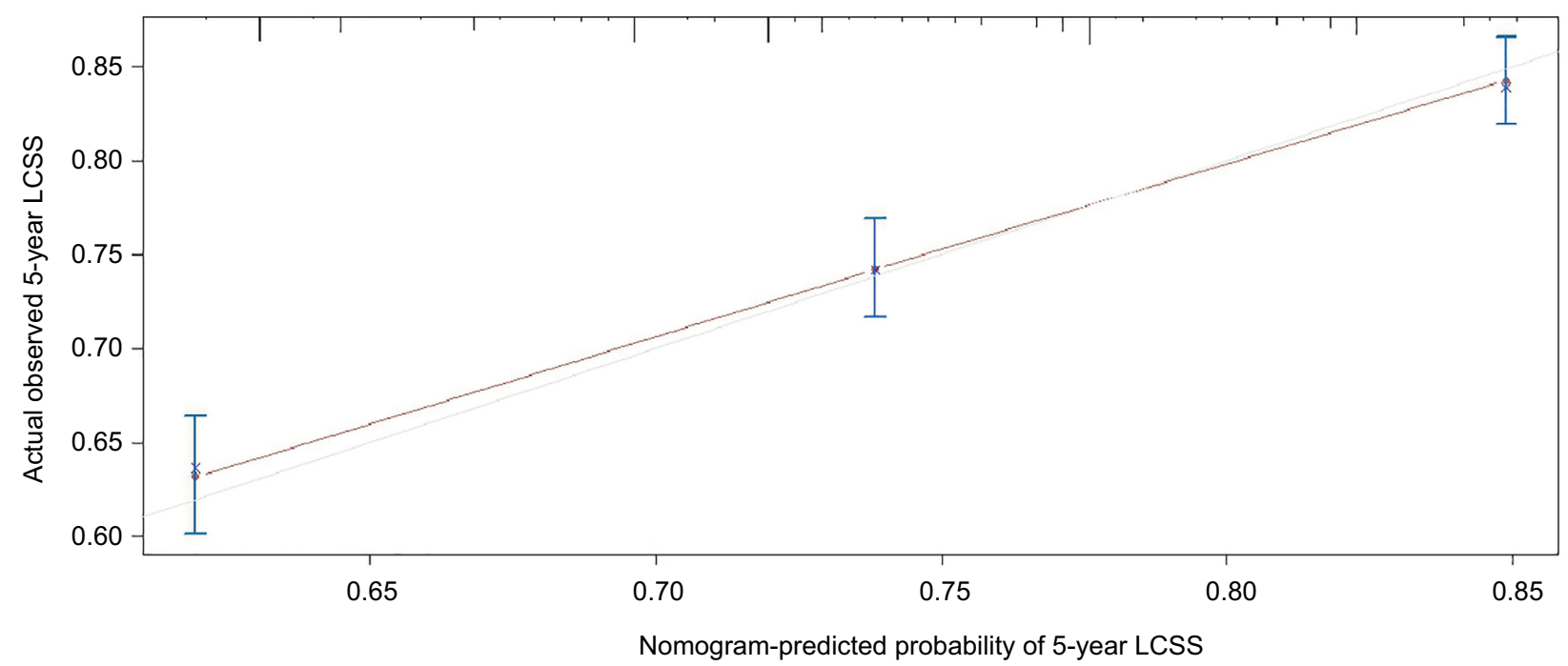

Figure 5 (A) Calibration curve of the nomogram for predicting 3-year LCSS rates of patients undergoing sublobar resection for stage IA NSCLC. (B) Calibration curve of the nomogram for predicting 5-year LCSS rates of patients undergoing sublobar resection for stage IA NSCLC.

Abbreviations: LCSS, lung cancer-specific survival; NSCLC, non-small-cell lung cancer.

who could tolerate either lobectomy or sublobar resection). Compared to wedge resection, segmentectomy is technically more challenging and involves removing a specific anatomic region of the lobe by carefully isolating and dividing the segmental artery, vein, and bronchus individually, and is a truly anatomical resection that usually includes wider resection margins and a more extensive intraparenchymal and hilar lymph nodes' dissection. ${ }^{19}$ Sienel et $\mathrm{al}^{20}$ found that segmentectomy had more lymph node numbers (12 vs 6) and demonstrated significantly better cancer-specific survival (71 vs $48 \%$ ) and lower local/regional recurrence (16\% vs $55 \%$ ) compared to wedge resection. The study by the American
College of Surgeons Surgical Oncology Group (ACOSG) (Z4032) evaluated three key features of sublobar resection in patients with stage I NSCLC. Significant differences were observed between patients with segmentectomy and those with wedge resection with regard to resection margin (1.5 vs $0.8 \mathrm{~cm}$ ), nodal upstaging ( 9 vs $1 \%$ ), and number of node stations sampled ( 3 vs 1 ). Remarkably, $41 \%$ of patients with wedge resection sampled zero nodes during the surgery compared with $2 \%$ of those with segmentectomy. ${ }^{21}$ Dziedzic et al, using the Polish National Lung Cancer Registry database, performed a retrospective analysis of the outcomes following the surgical treatment for stage I NSCLC from 2007 
to 2013. They demonstrated that patients who underwent segmentectomy had significantly improved 5 -year OS over wedge resection ( 78.3 vs $58.1 \%$ ). ${ }^{22}$

The degree of tumor differentiation is closely associated with lung cancer prognosis. Our study demonstrated that tumor differentiation was an independent prognostic factor for stage IA NSCLC. The degree of tumor differentiation is actually a reflection of tumor biological behavior characteristics. The first to seventh lung cancer TNM classification and staging system were in regard to the anatomical extent of tumor. However, the information regarding tumor differentiation grade reflecting malignant degree was not included..$^{23}$ It is encouraging to note that the TNM staging for esophageal cancer in the seventh edition incorporates tumor differentiation grade and was staged according to tumor differentiation grade and TNM. ${ }^{23}$ With the eighth edition of esophageal cancer staging, tumor differentiation grade was particularly important for pathological TNM staging of early esophageal cancer. ${ }^{24}$ In fact, the new classification for lung AC in 2011 was classified based on the biological behavior of the tumor. ${ }^{15}$ Based on the prognosis prediction value for different $\mathrm{AC}$ subtypes, several researchers have classified AC cancer into the following three different histological differentiations: the low level group had lepidic-predominant type, the medium level group consisted of acinar-predominant and papillarypredominant type, and the high level group had micropapillary-predominant and solid with mucin-predominant type. ${ }^{25}$ Such histological grading can guide surgical resection options and predict prognosis. It has been strongly suggested that the tumor differentiation degree should be considered for future updated versions.

Tumor size is closely associated with cancer prognosis and is an important independent predictor of outcomes in stage IA NSCLC. The results of our study further validated the common perception that the smaller the tumor, the better the prognosis. The eighth edition of the TNM classification for lung cancer divides T1 into three subgroups, ie, T1a, T1b, and $\mathrm{T} 1 \mathrm{c}$, based on each centimeter. This indicates that tumor size is an increasingly important prognostic factor and should be precisely measured, because small shifts in diameter may signify distinct prognosis. ${ }^{26}$ Based on the $\mathrm{T} 1$ subgroup cutoffs representing a logical degradation of survival as tumor size increases, we can easily select specific and individualized surgical treatment strategies. Dai et $\mathrm{al}^{27}$ concluded that segmentectomy should be recommended for T1b NSCLC patients who are unsuitable for lobectomy, whereas either segmentectomy or wedge resection could provide the same survival for T1a NSCLC patients. A recent publication by Cao et al compared the survival rates after lobectomy, segmentectomy, and wedge resection in patients classified according to the eighth edition for staging IA NSCLC. Results showed that lobectomy, segmentectomy, and wedge resection were comparable oncologic procedures for patients with stage IA NSCLC that was $1.0 \mathrm{~cm}$ or smaller. For tumors from 1.1 to $2.0 \mathrm{~cm}$, lobectomy and segmentectomy had similar survival rates but had better survival rates than that observed with wedge resection. For tumors from 2.1 to $3.0 \mathrm{~cm}$, lobectomy was still the standard surgical procedure. ${ }^{28}$

Sex and age are common independent prognostic factors for lung cancer and have been reported by several studies. Our study also showed similar results that female and younger patients were associated with better prognosis. The possible explanation for the correlation between sex and prognosis is that women smoke less and have fewer smoking-related chronic obstructive pulmonary diseases leading to a better prognosis. ${ }^{29}$ Another reason is that in females, AC is more frequent, EGFR mutation rates are higher, and the comprehensive treatment efficacy is better compared to males. ${ }^{30}$ The prognosis for NSCLC gets worse with increasing age. Older patients are more likely to die from non-lung cancer-related diseases such as cardiovascular disease. Groth et a ${ }^{31}$ reported that the risk of dying of cardiovascular and chronic pulmonary disease becomes nearly equivalent to dying of lung cancer with increasing age. However, compared to previous studies focusing only on OS for early-stage NSCLC, our study analyzed both OS and LCSS of stage IA NSCLC and investigated the differences in prognostic factors. The results showed that OS rates were worse compared to LCSS rates. Many factors could affect OS, which includes death caused by lung cancer and death caused by other diseases such as cardiovascular and cerebrovascular diseases, and are known as competitive risk factors. ${ }^{32}$ Zhou et al $^{33}$ demonstrated that $41.78 \%$ of stage I NSCLC death was attributed to causes other than the primary lung cancer. Our study showed that race, marital status, and pathological type were independent prognostic factors for OS but not LCSS. This may be interpreted using competitive risk factors. Zhou et $\mathrm{al}^{33}$ showed that stratification analysis for race, marriage and pathological types, and non-neoplastic competitive risk factors accounted approximately for 35,37 , and $40 \%$ of deaths. We are unable to get detailed information from the SEER data regarding patient's comorbidities such as cardiovascular and cerebrovascular diseases and other chronic diseases. Hence, age, race, and marital status could be proxy indicators for comorbidity.

Our study had several limitations. First, this is a retrospective study and the results may have inherent bias. Second, 
detailed data on patient's comorbidity, pulmonary function, performance status, the way in which the wedge or segmentectomy was performed (open vs video-assisted thoracic surgery), and recurrence rates could not be obtained from the SEER database. Due to this, we could not differentiate between radical and passive intent sublobectomy in our cohort. Third, the $C$-index of the formulated nomogram for predicting OS and LCSS was good but not excellent. Several other factors could have influenced the prognosis. Fourth, there was no external validation for this study. External validation is required to determine whether it could be applied to other patient groups. Our results should be further evaluated in prospective randomized trials.

\section{Conclusion}

This study used a large population-based cohort from the SEER database. We conclude that for patients with stage IA NSCLC undergoing sublobar resection, sex, age, race, marital status, pathology, differentiation, tumor size, and surgery type were independent prognostic factors for OS and sex, age, differentiation, tumor size, and surgery type were independent prognostic factors for LCSS. Based on these factors, we developed a convenient and visual nomogram to predict the 3- and 5-year OS and LCSS rates. The prediction outcome had a relatively good performance.

\section{Disclosure}

The authors report no conflicts of interest in this work.

\section{References}

1. Siegel RL, Miller KD, Jemal A. Cancer statistics, 2015. CA Cancer J Clin. 2015;65(1):5-29.

2. National Lung Screening Trial Research Team, Aberle DR, Adams $\mathrm{AM}$, et al. Reduced lung-cancer mortality with low-dose computed tomographic screening. N Engl J Med. 2011;365(5):395-409.

3. Ginsberg RJ, Rubinstein LV. Randomized trial of lobectomy versus limited resection for T1 N0 non-small cell lung cancer. Lung Cancer Study Group. Ann Thorac Surg. 1995;60(3):615-623.

4. Yendamuri S, Sharma R, Demmy M, et al. Temporal trends in outcomes following sublobar and lobar resections for small $(\leq 2 \mathrm{~cm})$ non-small cell lung cancers--a Surveillance Epidemiology End Results database analysis. J Surg Res. 2013;183(1):27-32.

5. Zhang Y, Sun Y, Chen H. A propensity score matching analysis of survival following segmentectomy or wedge resection in early-stage lung invasive adenocarcinoma or squamous cell carcinoma. Oncotarget. 2016;7(12):13880-13885.

6. Iasonos A, Schrag D, Raj GV, Panageas KS. How to build and interpret a nomogram for cancer prognosis. JClin Oncol. 2008;26(8):1364-1370.

7. National Cancer Institute [homepage on the Internet]. Surveillance, Epidemiology, and End Results. Available from: http://www.seer.cancer. gov. Accessed October 17, 2018.

8. Koay EJ, Teh BS, Paulino AC, Butler EB. A Surveillance, Epidemiology, and End Results analysis of small cell carcinoma of the bladder: epidemiology, prognostic variables, and treatment trends. Cancer. 2011;117(23):5325-5333.
9. Hamid MS, Shameem R, Gafoor K, et al. Non-Small-Cell Lung Cancer Clinicopathologic Features and Survival Outcomes in Asian Pacific Islanders Residing in the United States: A SEER Analysis. $J$ Cancer Epidemiol. 2015;2015:269304.

10. Cao J, Yuan P, Wang L, et al. Clinical nomogram for predicting survival of esophageal cancer patients after esophagectomy. Sci Rep. 2016;6:26684.

11. Molenaar RJ, Sidana S, Radivoyevitch T, et al. Risk of hematologic malignancies after radioiodine treatment of well-differentiated thyroid cancer. J Clin Oncol. 2018;36(18):1831-1839.

12. Wang M, Chen H, Wu K, Ding A, Zhang M, Zhang P. Evaluation of the prognostic stage in the 8th edition of the American Joint Committee on Cancer in locally advanced breast cancer: An analysis based on SEER 18 database. Breast. 2018;37:56-63.

13. Gao P, Huang XZ, Song YX, et al. Impact of timing of adjuvant chemotherapy on survival in stage III colon cancer: a population-based study. BMC Cancer. 2018;18(1):234.

14. Frank E.H.J. [homepage on the Internet]. Rms: Regression Modeling Strategies. R Package version 3.4-4. Available from: http://www.rproject.org/. Accessed October 17, 2018.

15. Travis WD, Brambilla E, Noguchi M, et al; American Thoracic Society. International Association for the Study of Lung Cancer/American Thoracic Society/European Respiratory Society: international multidisciplinary classification of lung adenocarcinoma: executive summary. Proc Am Thorac Soc. 2011;8(5):381-385.

16. Cao C, Tian DH, Wang DR, Chung CD, Gossot D, Bott M. Sublobar resections-current evidence and future challenges. $J$ Thorac Dis. 2017;9(12):4853-4855.

17. Chang JY, Senan S, Paul MA, et al. Stereotactic ablative radiotherapy versus lobectomy for operable stage I non-small-cell lung cancer: a pooled analysis of two randomised trials. Lancet Oncol. 2015;16(6):630-637.

18. Cao C, Chandrakumar D, Gupta S, Yan TD, Tian DH. Could less be more?-A systematic review and meta-analysis of sublobar resections versus lobectomy for non-small cell lung cancer according to patient selection. Lung Cancer. 2015;89(2):121-132.

19. Blasberg JD, Pass HI, Donington JS. Sublobar resection: a movement from the Lung Cancer Study Group. J Thorac Oncol. 2010;5(10):1583-1593.

20. Sienel W, Dango S, Kirschbaum A, et al. Sublobar resections in stage IA non-small cell lung cancer: segmentectomies result in significantly better cancer-related survival than wedge resections. Eur J Cardiothorac Surg. 2008;33(4):728-734.

21. Kent M, Landreneau R, Mandrekar S, et al. Segmentectomy versus wedge resection for non-small cell lung cancer in high-risk operable patients. Ann Thorac Surg. 2013;96(5):1747-1754; discussion $1754-1755$.

22. Dziedzic R, Zurek W, Marjanski T, et al. Stage I non-small-cell lung cancer: long-term results of lobectomy versus sublobar resection from the Polish National Lung Cancer Registry. Eur J Cardiothorac Surg. 2017;52(2):363-369.

23. Edge SB, Byrd D, Compton CC, Fritz AG, Greene FL, Trotti A, editors. American Joint Committee on Cancer Cancer Staging Manual. 7th ed. New York, NY: Springer-Verlag; 2010.

24. Rice TW, Gress DM, Patil DT, et al. Cancer of the esophagus and esophagogastric junction-Major changes in the American Joint Committee on Cancer eighth edition cancer staging manual. CA Cancer J Clin. 2017;67(4):304-317.

25. Russell PA, Wainer Z, Wright GM, et al. Does lung adenocarcinoma subtype predict patient survival?: A clinicopathologic study based on the new International Association for the Study of Lung Cancer/ American Thoracic Society/European Respiratory Society international multidisciplinary lung adenocarcinoma classification. JThorac Oncol. 2011;6(9):1496-1504.

26. Rami-Porta R, Asamura H, Travis WD, Rusch VW. Lung cancer - major changes in the American Joint Committee on Cancer eighth edition cancer staging manual. CA Cancer J Clin. 2017;67(2):138-155. 
27. Dai C, Shen J, Ren Y, et al. Choice of Surgical Procedure for Patients With Non-Small-Cell Lung Cancer $\leq 1 \mathrm{~cm}$ or $>1$ to $2 \mathrm{~cm}$ Among Lobectomy, Segmentectomy, and Wedge Resection: A Population-Based Study. J Clin Oncol. 2016;34(26):3175-3182.

28. Cao J, Yuan P, Wang Y, et al. Survival Rates After Lobectomy, Segmentectomy, and Wedge Resection for Non-Small Cell Lung Cancer. Ann Thorac Surg. 2018;105(5):1483-1491.

29. Shankar A, Yuan JM, Koh WP, Lee HP, Yu MC. Morbidity and mortality in relation to smoking among women and men of Chinese ethnicity: the Singapore Chinese Health Study. Eur J Cancer. 2008;44(1):100-109.

30. Sasaki H, Shimizu S, Endo K, et al. EGFR and erbB2 mutation status in Japanese lung cancer patients. Int J Cancer. 2006;118(1):180-184.
31. Groth SS, Rueth NM, Hodges JS, et al. Conditional cancer-specific versus cardiovascular-specific survival after lobectomy for stage I nonsmall cell lung cancer. Ann Thorac Surg. 2010;90(2):375-382.

32. Kutikov A, Egleston BL, Wong YN, Uzzo RG. Evaluating overall survival and competing risks of death in patients with localized renal cell carcinoma using a comprehensive nomogram. J Clin Oncol. 2010;28(2):311-317.

33. Zhou H, Zhang Y, Qiu Z, et al. Nomogram to Predict Cause-Specific Mortality in Patients With Surgically Resected Stage I Non-SmallCell Lung Cancer: A Competing Risk Analysis. Clin Lung Cancer. 2018;19(2):e195-e203. 


\section{Supplementary materials}
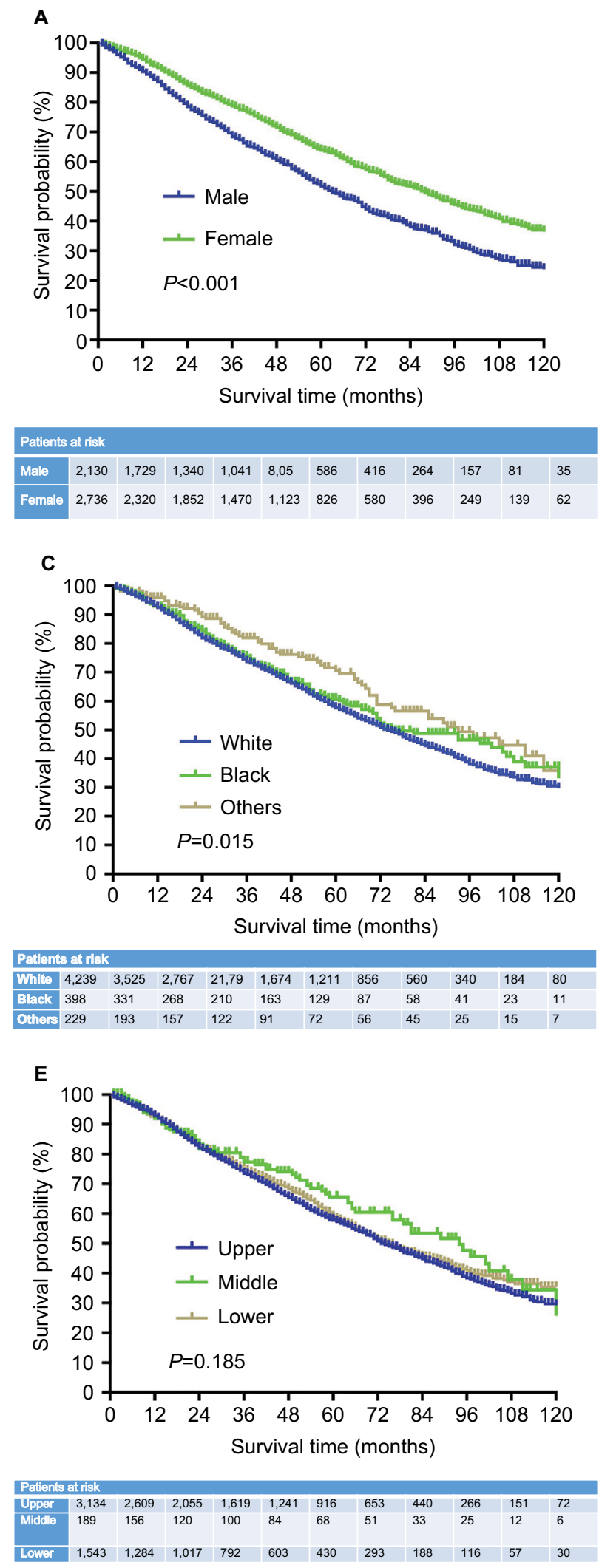

Figure SI (Continued)
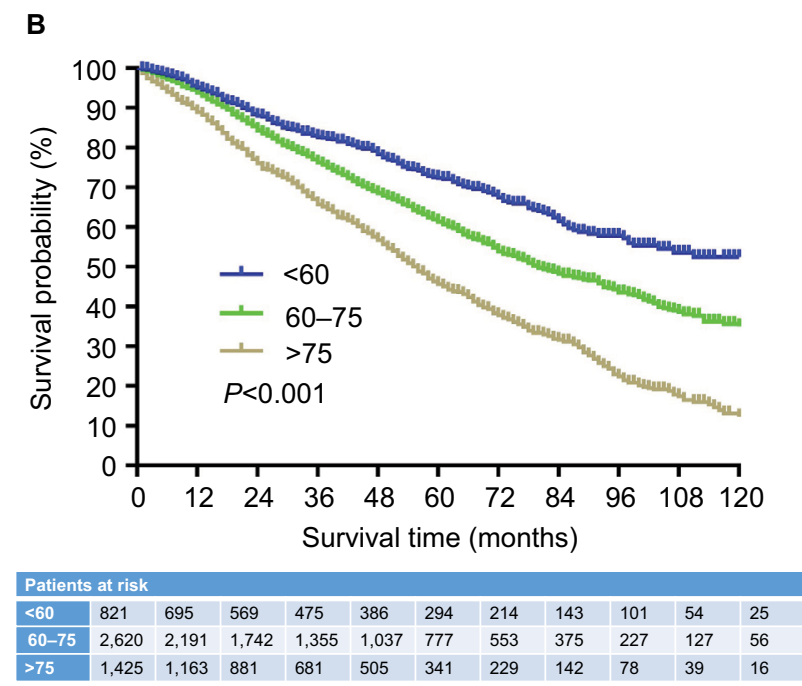

D
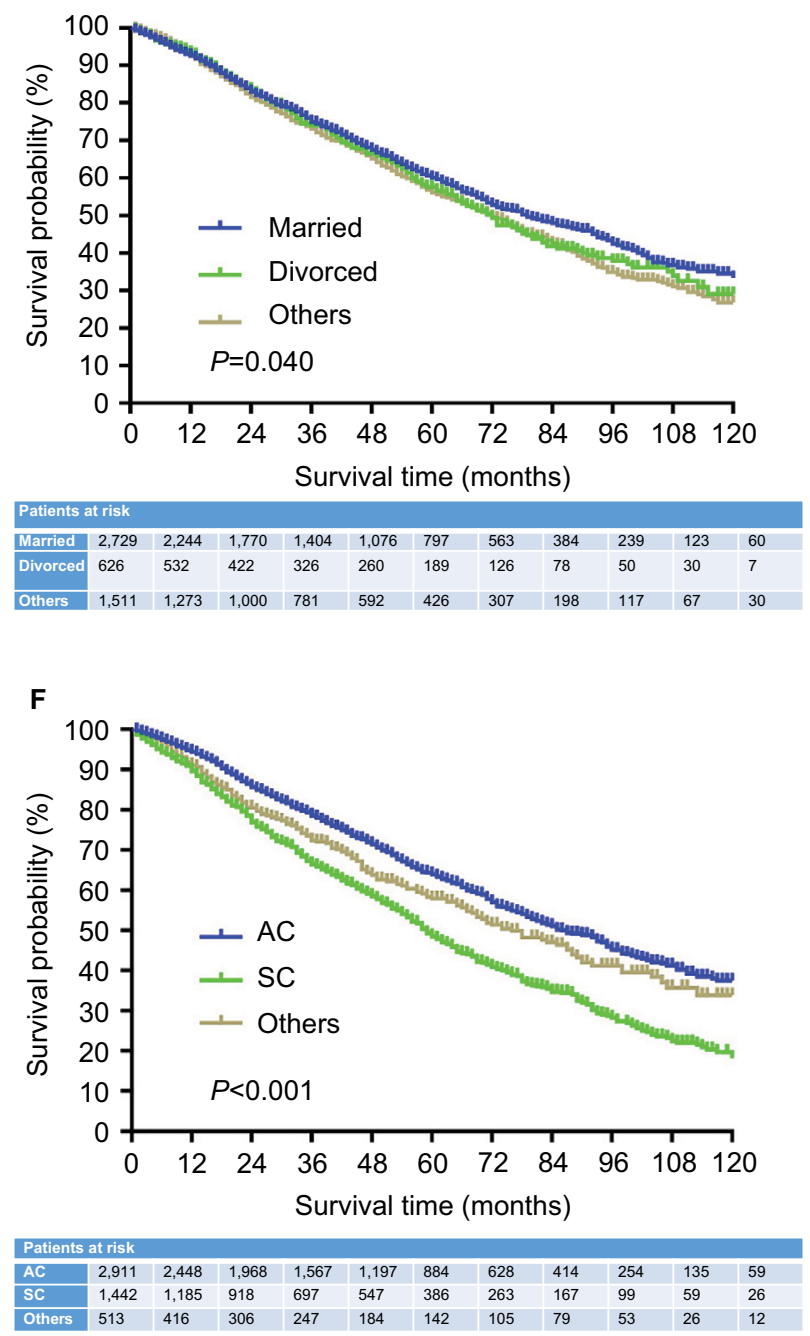

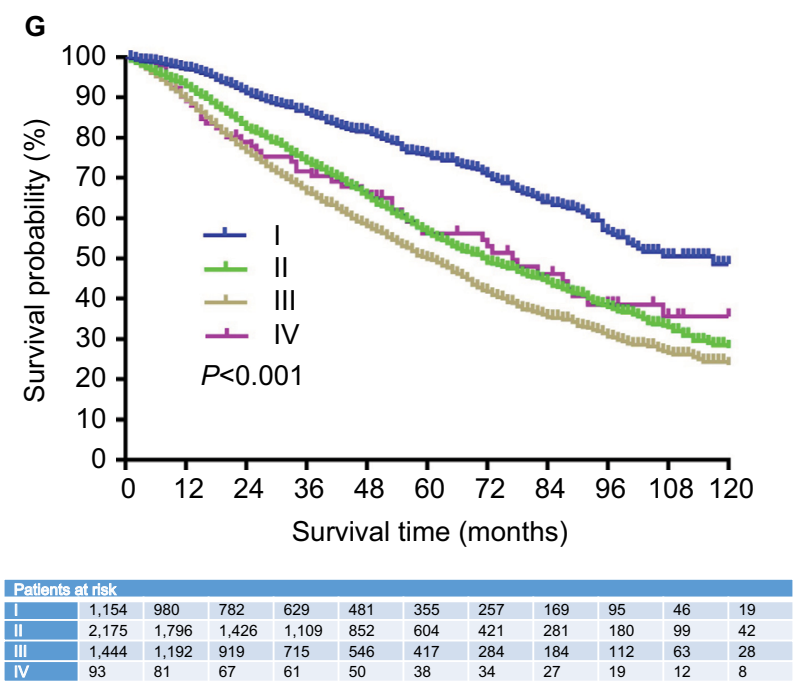

H

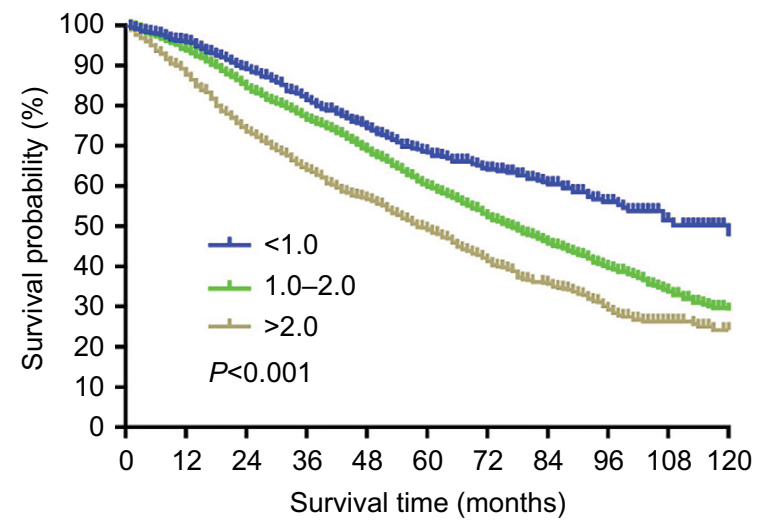

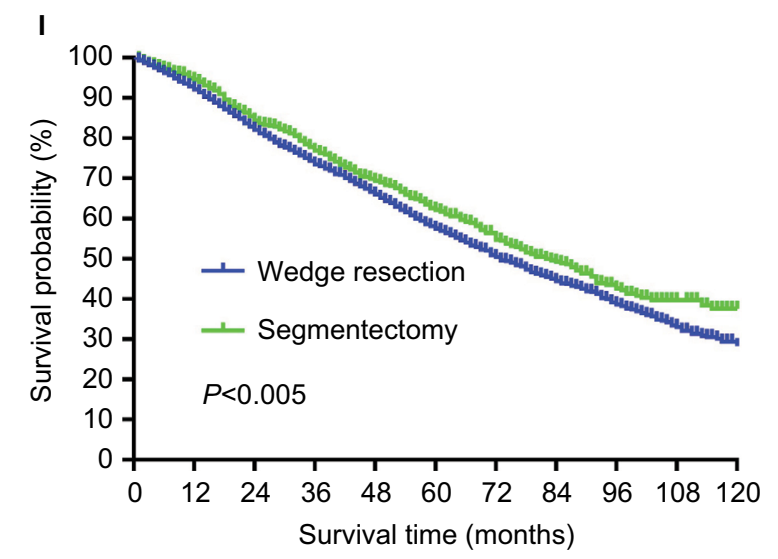

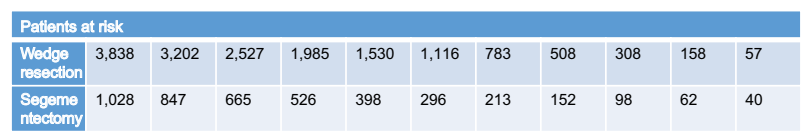

Figure SI Overall Kaplan-Meier survival curves for patients according to (A) sex, (B) age, (C) race, (D) marital status, (E) lobe, (F) pathology, (G) differentiation, (H) tumor size, and (I) surgery.

Abbreviations: AC, adenocarcinoma; SC, squamous cell carcinoma.

A

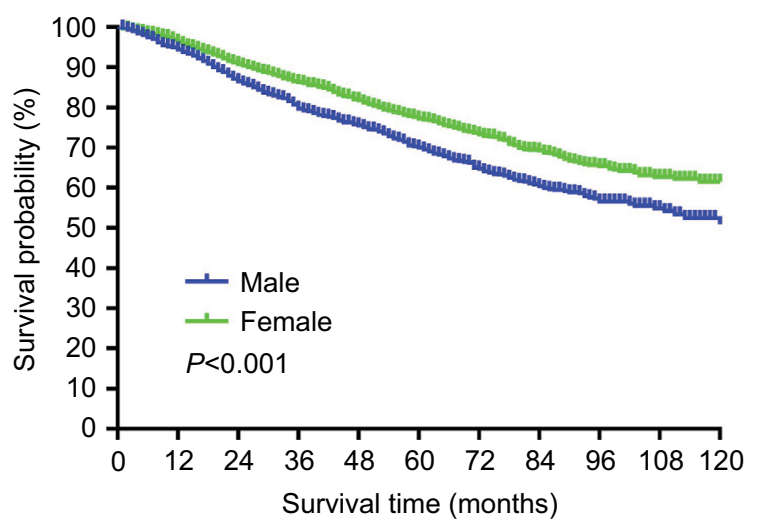

Patients at risk

$\begin{array}{lllllllllllll}\text { Male } & 2,130 & 1,729 & 1,340 & 1,041 & 805 & 586 & 416 & 264 & 157 & 81 & 35\end{array}$

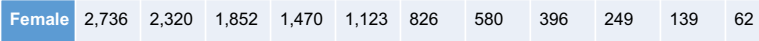

Figure S2 (Continued)
B

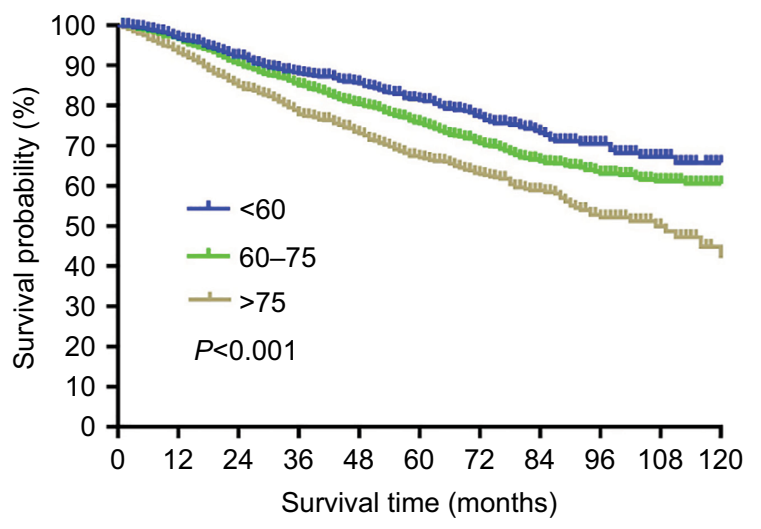

Patients at risk \begin{tabular}{|l|l|l|l|l|l|l|l|l|l|l|l|}
\hline$<60$ & 821 & 695 & 569 & 475 & 386 & 294 & 214 & 143 & 101 & 54 & 25 \\
\hline $60-75$ & 2,620 & 2,191 & 1,742 & 1,355 & 1,037 & 777 & 553 & 375 & 227 & 127 & 56 \\
\hline
\end{tabular} \begin{tabular}{|l|l|l|l|l|l|l|l|l|l|l|l|}
\hline$>75$ & 1,425 & 1,163 & 881 & 681 & 505 & 341 & 229 & 142 & 78 & 39 & 16 \\
\hline
\end{tabular} 
C

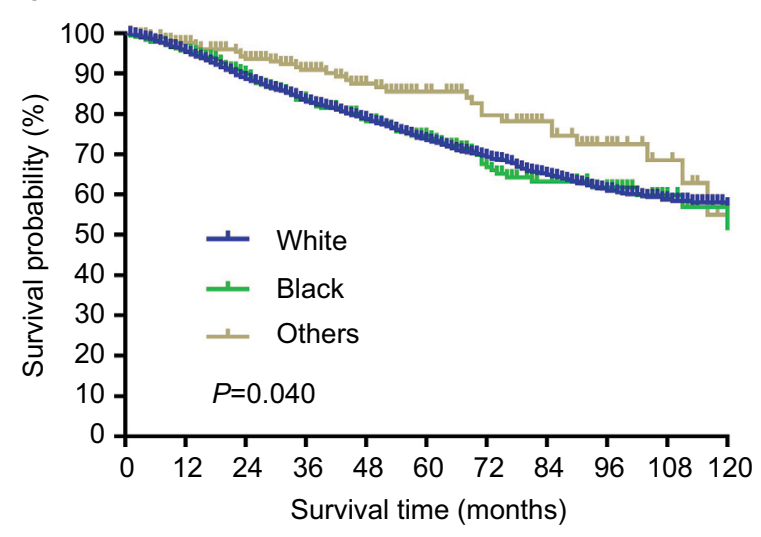

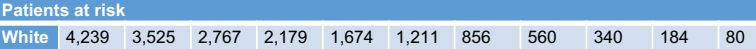
\begin{tabular}{|l|l|l|l|l|l|l|l|l|l|l|l|}
\hline White & 4,239 & 3,525 & 2,767 & 2,179 & 1,674 & 1,211 & 856 & 560 & 340 & 184 & 80 \\
\hline Black & 398 & 331 & 268 & 210 & 163 & 129 & 87 & 58 & 41 & 23 & 11 \\
\hline Others & 229 & 193 & 157 & 122 & 91 & 72 & 56 & 45 & 25 & 15 & 7 \\
\hline
\end{tabular}

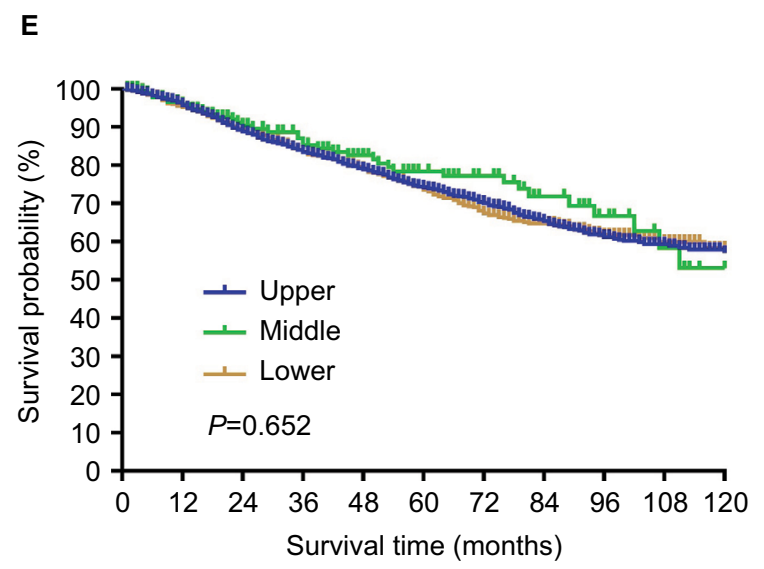

Patients at risk

\begin{tabular}{l|l|l|l|l|l|l|l|l|l|l|l|} 
Upper & 3,134 & 2,609 & 2,055 & 1,619 & 1,241 & 916 & 653 & 440 & 266 & 151 & 72
\end{tabular} \begin{tabular}{|l|l|l|l|l|l|l|l|l|l|l|l|}
\hline Middle & 189 & 156 & 120 & 100 & 84 & 68 & 51 & 33 & 25 & 12 & 6
\end{tabular} \begin{tabular}{|l|l|l|l|l|l|l|l|l|l|l|l|}
\hline Lower & 1,543 & 1,284 & 1,017 & 792 & 603 & 430 & 293 & 188 & 116 & 57 & 30 \\
\hline
\end{tabular}

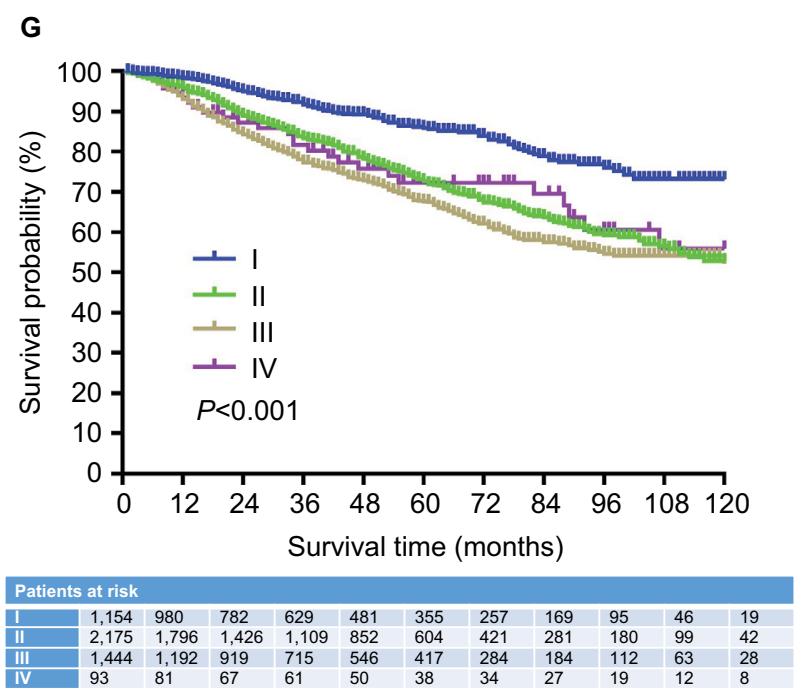

D

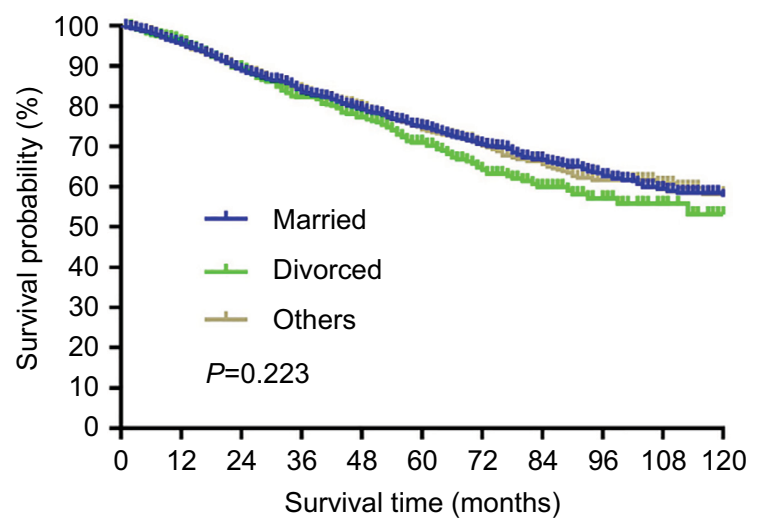

Patients at risk

\begin{tabular}{|l|l|l|l|l|l|l|l|l|l|l|l|}
\hline Married & 2,729 & 2,244 & 1,770 & 1,404 & 1,076 & 797 & 563 & 384 & 239 & 123 & 60 \\
\hline
\end{tabular} \begin{tabular}{|l|l|l|l|l|l|l|l|l|l|l|l|} 
Divorced 626 & 532 & 422 & 326 & 260 & 189 & 126 & 78 & 50 & 30 & 7
\end{tabular} \begin{tabular}{|l|l|l|l|l|l|l|l|l|l|l|l|}
\hline Others & 1,511 & 1,273 & 1,000 & 781 & 592 & 426 & 307 & 198 & 117 & 67 & 30 \\
\hline
\end{tabular}
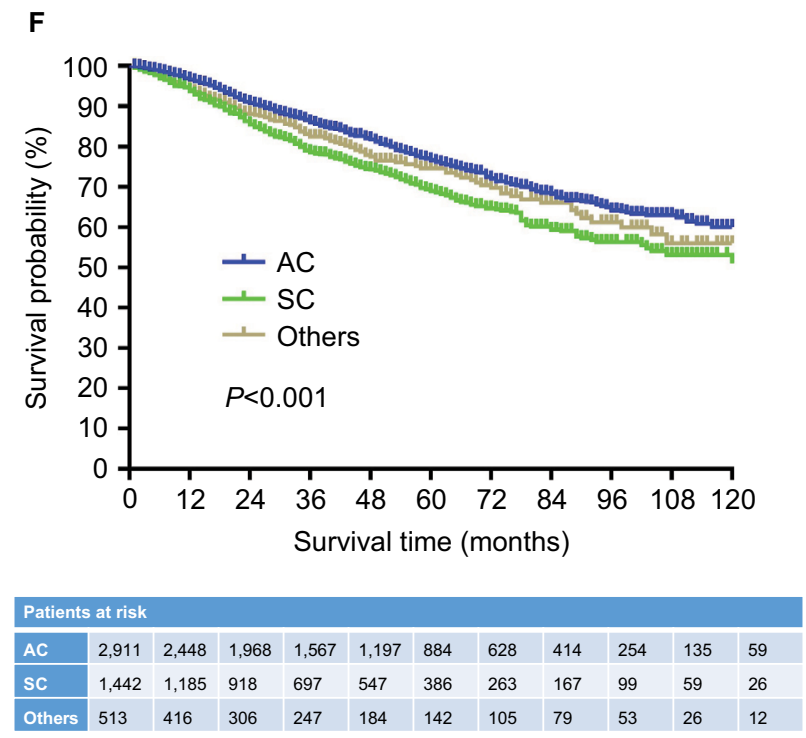

H

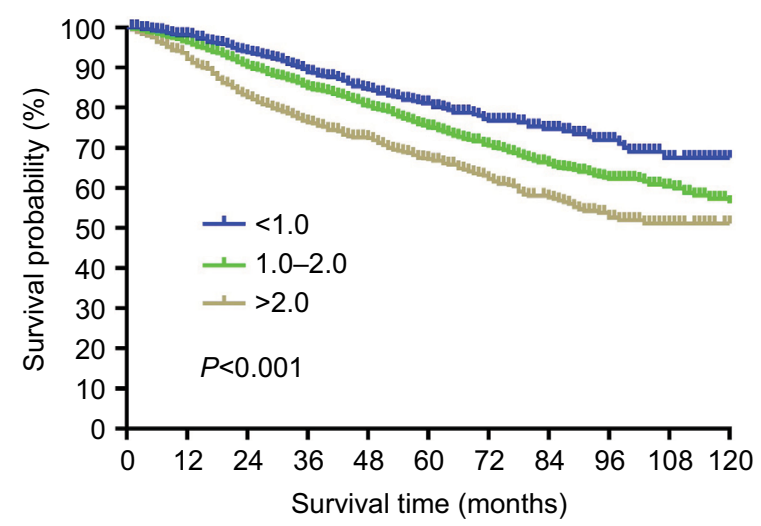

Patients at risk

\begin{tabular}{l|l|l|l|l|l|l|l|l|l|l|l|}
\hline$<1.0$ & 859 & 735 & 599 & 465 & 347 & 262 & 189 & 136 & 86 & 43 & 19 \\
\hline
\end{tabular}

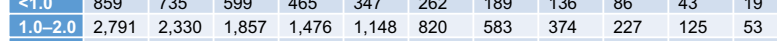
\begin{tabular}{|l|l|l|l|l|l|l|l|l|l|l|l|}
\hline$>2.0$ & 1,216 & 984 & 736 & 570 & 433 & 330 & 224 & 150 & 93 & 52 & 25 \\
\hline
\end{tabular}

Figure S2 (Continued) 
I

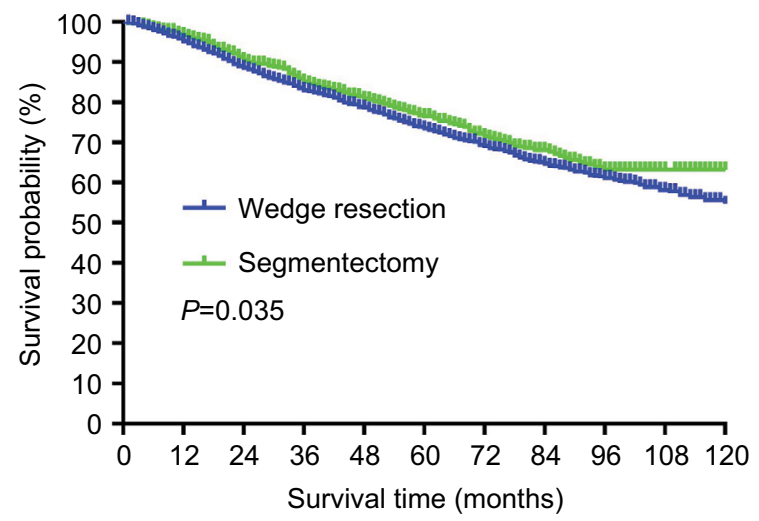

\begin{tabular}{|l|l|l|l|l|l|l|l|l|l|l|l|}
\hline Patients at risk \\
\begin{tabular}{|l|l|l|l|l|l|l|l|} 
Wedge \\
resection
\end{tabular} & 3,838 & 3,202 & 2,527 & 1,985 & 1,530 & 1,116 & 783 & 508 & 308 & 158 & 57 \\
\hline $\begin{array}{l}\text { Segme } \\
\text { ntectomy }\end{array}$ & 1,028 & 847 & 665 & 526 & 398 & 296 & 213 & 152 & 98 & 62 & 40 \\
\hline
\end{tabular}

Figure S2 Lung cancer-specific Kaplan-Meier survival curves for patients according to (A) sex, (B) age, (C) race, (D) marital status, (E) lobe, (F) pathology, (G) differentiation, (H) tumor size, and (I) surgery.

Abbreviations: AC, adenocarcinoma; SC, squamous cell carcinoma.

\section{Publish your work in this journal}

Cancer Management and Research is an international, peer-reviewed open access journal focusing on cancer research and the optimal use of preventative and integrated treatment interventions to achieve improved outcomes, enhanced survival and quality of life for the cancer patient. The manuscript management system is completely online and includes a very quick and fair peer-review system, which is all easy to use. Visit http://www.dovepress.com/testimonials.php to read real quotes from published authors. 